\title{
A NOÇÃO DE EXPERIÊNCIA EM HEGEL COMO CRÍTICA IMANENTE
}

\author{
Carla Vanessa Brito De Oliveira ${ }^{1}$
}

RESUMO: É escopo do presente artigo a elucidação da noção de experiência (Erfahrung) em Hegel, como crítica imanente, na medida em que a mesma se volta criticamente para pressupostos epistemológicos sustentados na crítica transcendental kantiana. A partir, sobretudo, do exame da Introdução da Fenomenologia do Espírito (1807), busca-se elucidar que a experiência em Hegel se trata da experiência da consciência que, em seu "caminho para a ciência", se perfaz na condição de uma crítica imanente. Para tanto, é mister compreender que a experiência da consciência é a própria experiência do saber, pois, para Hegel, a consciência sempre se põe em uma relação mútua com o seu nãoidêntico, o objeto, de modo a instituir o momento do saber e o momento do objeto reciprocamente e, assim, entregue a essa relação de simultânea oposição e complementariedade, examina a si mesma. 
PALAVRAS-CHAVE: Crítica; Conhecimento; Experiência; Hegel.

ABSTRACT: This article presents the notion of experience (Erfahrung) in Hegel as a immanent critique. We show that the immanent epistemological critique criticizes the presuppositions of Kant's transcendental critique. For this, we will examine the Introduction of Phenomenology of Spirit (1807), comprising that the experience of counsciousness is the experiente of knowledge.

KEYWORDS: Critical; Knowledge; Experience; Hegel. 
É escopo do presente artigo a elucidação da noção de experiência (Erfahrung) em Hegel, como crítica imanente, na medida em que a mesma se volta criticamente para os pressupostos sustentados na crítica transcendental kantiana. A partir, sobretudo, do exame da Introdução da Fenomenologia do Espírito (1807), busca-se elucidar que a experiência em Hegel trata da experiência da consciência que, em seu "caminho para a ciência", se perfaz na condição de uma crítica imanente. Para tanto, é mister compreender que a experiência da consciência engendra a si mesma como experiência do saber pois, para Hegel, a consciência sempre se põe em uma relação mútua com o seu não-idêntico, o objeto, de modo a instituir o momento do saber (em seu sentido fenomênico) e o momento do objeto reciprocamente e, assim, entregue a essa relação de simultânea oposição e complementariedade, examina a si mesma ao mesmo tempo em que verifica a correspondência entre seus dois momentos. O caminho de formação do saber, nesse sentido, é imanente ao exame do próprio saber.

O exame do conhecimento em Hegel, conforme a Introdução da Fenomenologia, se traduz como crítica imanente especialmente ao não importar nada de fora do próprio movimento dialético da consciência, o que significa redefinir o próprio sentido de crítica filosófica: não se trata aqui de colocar a razão em um tribunal, a fim de delimitar seu conhecimento possível, independentemente da 
experiência, mas de deixar que o próprio conceito de saber se produza a partir da experiência mesma de crítica que a consciência empreende em si mesma.

Ao voltar-se para a própria constituição do saber em devir, na história de formação da consciência, a crítica imanente incide sobre os pressupostos da crítica transcendental kantiana, os quais são utilizados para oferecer uma concepção de conhecimento cujo sentido, para Hegel, é de um conhecimento meramente representativo. Ademais, os limites da experiência possível, ao serem dados aprioristicamente, pressupõem, para a consecução do conhecimento, a radical separação entre sujeito e objeto, bem como pressupõem o conjunto de objetos que podem ser conhecidos.

Para Hegel, por seu turno, é apenas fenomenologicamente que a consciência adquire seu conceito de saber, sendo necessária, nesse sentido, a entrega da consciência a sua (auto) exposição. Isto significa admitir o conhecimento através do processo formativo da própria consciência, o qual é realizado pelo julgamento das formas fenomênicas de saber, pois a entrega ao conhecimento compreende examinar o saber que aparece. Em seu percurso para a consciência filosófica, a consciência fenomênica assume ainda uma sucessão de figuras, as quais constituem "a história pormenorizada da formação da consciência mesma para a Ciência” (HEGEL, 1988, p. 48). 
No que se refere a crítica kantiana, ela se constrói pelo estabelecimento prévio do que pode ser conhecido, sendo necessário no julgamento da razão ter um acordo sobre "o que posso saber"; a crítica hegeliana, por sua vez, se constitui fenomenologicamente ao acompanhar o movimento que a consciência realiza em si mesma em seu processo formativo. Se o conhecimento em Kant, definido como unidade sintética da multiplicidade, tem sua síntese efetuada por intermédio da consciência transcendental, também denominada de "eu transcendental" e que constitui a unidade lógica que efetua o próprio conhecimento, em Hegel, o conhecimento só pode ser constituído por um processo formativo da consciência. Ou seja, a crítica hegeliana se caracteriza pela apreensão do saber como fenômeno em devir, em seu aparecer para a consciência como processo, sem dispor previamente de um "eu a priori" ou de um sujeito transcendental.

\section{A CRÍTICA TRANSCENDENTAL KANTIANA}

O desenvolvimento pleno da concepção de conhecimento em Kant é verificado em sua obra Crítica da Razão Pura (1787). Essa obra, que constitui o projeto crítico kantiano, objetiva erigir uma crítica à razão, de modo a delimitar o campo possível do conhecimento teórico frente 
ao dogmatismo metafísico, ou seja, aquela postura de sustentação de determinadas suposições básicas sem, contudo, a passagem das mesmas pelo crivo da razão. Para Kant, a metafísica, em sua incansável interrogação pelo incondicionado, ultrapassaria os limites da experiência de modo a se precipitar em contradições; embora seja necessário buscar pelos primeiros princípios, não decorre disso que seja possível conhecê-los, visto que, para tanto, a razão exceda totalmente a experiência. Nesse sentido, a metafísica está além da natureza e, desse modo, é impossível que ela seja ciência devido à sua própria condição de transcendência da experiência: "não são obstáculos externos que se opõem à metafísica. É sua própria natureza, ou seja, $o$ conhecimento independente da experiência ou conhecimento puro da razão, que a estorva [...]" (HÖFFE, 2005, p. 35).

A fim de liberar a metafísica da sua situação considerada aporética, Kant estabelece um tribunal com o objetivo de examinar as possibilidades de um conhecimento puro da razão (Cf. HÖFFE, 2005, p. 38). Tal exame se chama "crítica" e envolve "discernimento e justificação" (Cf. HÖFFE, 2005, p. 38). A crítica da razão pura não objetiva a sua condenação, mas assume a função de determinar a sua fonte, a sua extensão e o seu limite. Diz o filósofo no Prefácio à Primeira Edição (1781): 
[a crítica] é um convite à razão para de novo empreender a mais difícil das suas tarefas, a do conhecimento de si mesma e da constituição de um tribunal que lhe assegure as pretensões legítimas e, em contrapartida, possa condenar-lhe todas as presunções infundadas; e tudo isto, não por decisão arbitrária, mas em nome das suas leis eternas e imutáveis. Esse tribunal outra coisa não é que a própria Crítica da Razão Pura.

Por uma crítica assim, não entendo uma crítica de livros e de sistemas, mas da faculdade da razão em geral, com respeito a todos os conhecimentos a que pode aspirar, independentemente de toda experiência; portanto, a solução do problema da possibilidade ou impossibilidade de uma metafísica em geral e a determinação tanto das suas fontes como da sua extensão e limites; tudo isto, contudo, a partir de princípios (KANT, 2001, AXII).

No Prefácio à Segunda Edição, Kant destaca ainda:

Mas que tesouro é este, perguntar-se-á, que pretendemos legar à posterioridade com semelhante metafísica purificada pela crítica e conduzida por esse meio a um estado duradouro? Com um lance superficial de olhos sobre esta obra, acreditar-se-á perceber que sua utilidade seja somente negativa, ou 
seja, de jamais ousarmos elevar-nos com a razão especulativa acima dos limites da experiência, esta é, na verdade, sua primeira utilidade. Ela se tornará porém imediatamente positiva se nos dermos conta que os princípios, com os quais a razão especulativa se aventura além dos seus limites, de fato têm como inevitável resultado, se o observarmos mais de perto, não uma ampliação, mas uma restrição do uso da nossa razão na medida em que realmente ameaçam estender sobre todas as coisas os limites da sensibilidade à qual pertencem propriamente, ameaçando assim anular o uso puro (prático) da razão (KANT, 1999, p. 42).

A crítica, portanto, cumpre uma função tanto negativa como positiva, revelando tanto os limites da razão como o seu campo legítimo de atuação. Porém, a utilidade positiva da crítica reserva-se exclusivamente para o uso prático da razão, de modo que, no âmbito epistemológico, a crítica é restritiva. Não obstante, tendo em vista que a possibilidade de um conhecimento puro da razão, que ultrapassa o domínio da experiência, só pode ser investigada pela própria razão pura, temos que, em síntese, “a Crítica da razão pura é o autoexame e a autolegitimação da razão independente da experiência” (HÖFFE, 2005, p. 38). Assim, "é na autocrítica que a razão manifesta o seu poder; mas este poder serve para sua autolimitação" (HÖFFE, 2005, p. 38). 
De fato, é pela limitação, pela restrição, que a crítica da razão pura estabelece $o$ alcance da sua atividade.

Kant arquiteta seu projeto crítico com o objetivo principal de fundamentar a filosofia em bases científicas. A metafísica, devido à sua natureza transcendente, não logra a condição de fundamento científico, de modo a ser as ciências modernas, notadamente as ciências naturais, aquelas a oferecerem a referência metodológica para a "revolução do pensamento", para que a filosofia siga o caminho seguro de uma ciência. A ideia de uma "revolução copernicana do pensamento", seguramente, para Kant, colocaria a filosofia no caminho do progresso científico, onde sua execução dependeria de uma espécie de método procedimental:

Fazer progressos só é possível quando se procede conforme a um plano e seguem metas e quando os especialistas na matéria concordam no que se refere à forma do procedimento. Mas na metafísica não existe um consenso sobre o método; por isso, ela não pode esperar nenhum progresso, apesar do esforço de dois mil anos. Na Crítica da razão pura Kant pretende fornecer esse novo método (HÖFFE, 2005, p. 41).

Isso posto, considerando que a concepção de conhecimento kantiana está circunscrita ao projeto crítico 
da razão pura, entende-se porque a epistemologia em Kant se apresenta também como instrumental.

O caminho seguro para a ciência é tomado por Kant em referência às ciências que lograram sucesso, a exemplo da lógica, a qual se caracteriza pelas regras formais do pensamento; e a exemplo das "ciências reais", aquelas que se ocupam de objetos, como a matemática e as ciências naturais, especialmente a física. Estas encontram o perseguido caminho seguro da ciência quando se propõem a uma "revolução no seu modo de pensar". Ou seja, a ideia de ciência a ser buscada compreende uma estrutura básica traduzida por uma "revolução do modo de pensar" (HÖFFE, 2005, p. 42). Em se tratando das ciências naturais, a ideia de que a razão só conhece da natureza o que ela mesma produz segundo o seu próprio projeto. Diz Kant no Segundo Prefácio:

Quando Galileu deixou as suas esferas rolar sobre o plano inclinado com um peso por ele mesmo escolhido, ou quando Torricelli deixou o ar carregar um peso de antemão pensado como igual o de uma coluna de água conhecida por ele, ou quando ainda mais tarde Stahal transformou metais em cal e esta de novo em metal retirando-lhes ou restituindo-lhes algo: assim acendeu-se uma luz para todos os pesquisadores da natureza. Compreenderam que a 
razão só discerne o que ela mesmo produz segundo seu projeto, que ela tem de ir à frente com princípios dos seus juízos segundo leis constantes e obrigar a natureza a responder às suas perguntas, mas sem ter de deixar-se conduzir somente por ela como se estivesse presa a um laço; pois do contrário observações causais, feitas sem um plano previamente projetado, não se interconectariam numa lei necessária, coisa que a razão todavia procura e necessita. A razão tem que ir à natureza tendo numa das mãos os princípios unicamente segundo os quais fenômenos concordantes entre si podem valer como leis, e na outra o experimento que ela imaginou segundo aqueles princípios, na verdade para ser instruída pela natureza, não porém na qualidade de um aluno que se deixa ditar tudo o que professor quer, mas na de um juiz nomeado que obriga as testemunhas a responder às perguntas que lhes propõe. E assim até mesmo a Física deve a tão vantajosa revolução na sua maneira de pensar apenas à ideia de procurar na natureza (não lhe imputar), segundo o que a própria razão coloca nela, aquilo que precisa aprender da mesma maneira e sobre o que nada saberia por si própria” (KANT, 1999, p. 37-38).

Ora, se a metafísica quer alcançar a dignidade de uma ciência, ela também precisa de uma revolução em seu modo de pensar, a saber, uma revolução que coloque o sujeito 
cognoscente como regulador dos objetos. Para Kant, trata-se de uma proposta que deve ser experimentada pela razão a fim de verificar seu sucesso. Comparada com a descoberta de Copérnico, o experimento da razão fica conhecido como a "revolução copernicana do pensar". De acordo com Höffe, Copérnico, para o filósofo:

[...] supera a perspectiva de uma consciência natural, evidenciando o caráter ilusório da ideia da rotação do Sol em torno da Terra, encontrando a verdade, antes, numa nova posição, não mais natural, do sujeito ante seu objeto, ou seja, ante o movimento do Sol e dos planetas. De modo semelhante, na Crítica da razão pura, Kant pretende apresentar mais que uma mera refutação de teorias metafísicas. Ele supera não apenas o racionalismo, o empirismo e o ceticismo; funda, sobretudo, uma nova posição do sujeito em relação à objetividade. $\mathrm{O}$ conhecimento não deve mais regular-se pelo objeto, mas sim o objeto pelo nosso conhecimento (HÖFFE, 2005, p. $44)$.

Neste ponto, tendo em vista que a revolução do pensar promovida pela filosofia deve ser aquela que admite o objeto regulado pelo nosso conhecimento, observamos como se depreende do projeto crítico o idealismo transcendental kantiano, este que pretende fornecer as condições a priori da 
possibilidade do conhecimento, as quais devem ser dadas no sujeito puro. Conforme diz Höffe, a revolução kantiana exige que a razão se livre do realismo gnosiológico, de modo que a objetividade, posta pela necessidade e universalidade, surja no sujeito cognoscente (Cf. HÖFFE, 2005, p. 44).

Tratemos do criticismo kantiano, pois, como crítica transcendental nos termos aqui expostos. ${ }^{2}$ Diferente de transcendente, transcendental não se refere a um mundo suprassensível. Embora o termo "transcendental" em Kant compreenda um domínio que ultrapassa a experiência, esse ultrapassar compete na investigação das condições prévias da experiência (Cf. HÖFFE, 2005, p. 59). Assim, em Kant, o transcendental se distingue do empírico, do metafísico e, também, do lógico (HOWARD, 2000, p. 311). O filósofo, na Introdução da Crítica da Razão Pura denomina por transcendental, pois, "todo o conhecimento que em geral se ocupa não tanto com objetos, mas com nosso modo de conhecimento de objetos na medida em que este deve ser possível a priori" (KANT, 1999, p. 65). Nesse sentido, é plausível afirmar que conhecimento transcendental constitui uma "teoria do a priori", da possibilidade de conhecimento a priori (Cf. HÖFFE, 2005, p. 60).

Nesse sentido, é tarefa da crítica transcendental demonstrar que certas representações não possuem origem empírica, como também, não obstante, lhe compete demonstrar a possibilidade pela qual essas representações 
podem se referir a priori a objetos empíricos. É oportuno relembrarmos a célebre passagem de Kant sobre o tempo e a origem do conhecimento, a saber: "Que todo o nosso conhecimento começa com a experiência, não há dúvida alguma [...]. Mas embora todo o nosso conhecimento comece com a experiência, nem por isso todo ele se origina justamente da experiência" (KANT, 1999, 53).

$\mathrm{Na}$ Analítica Transcendental, Kant define precisamente o sentido de conhecimento, isto é, definindo-o como conhecimento empírico, o qual, contudo, se distingue de uma concepção empirista trivial, visto que, para Kant, conhecimento empírico compreende objetos pensados por categorias, as quais possuem origem a priori, na faculdade do entendimento. Por sua vez, a possibilidade do conhecimento empírico depende da aplicação potencial das categorias, de modo que temos efetivamente conhecimento a partir da "síntese das percepções" promovida pelo entendimento. O filósofo comenta:

[...] este conhecimento, limitado meramente a objetos da experiência, não é por isso extraído toda da experiência, mas tanto as intuições puras como os conceitos puros do entendimento são elementos do conhecimento encontrados a priori em nós (KANT, 1999, p. 137). 
Assim, a concordância necessária da experiência com os conceitos de seus objetos, deriva do fato desses conceitos (categorias) tornarem possível a própria experiência, visto que "as categorias contêm, por parte do entendimento, os fundamentos da possibilidade de toda experiência em geral" (KANT, 1999, p. 138). Portanto, se depreende da epistemologia transcendental a noção de um conhecimento cuja possibilidade é determinada de modo apriorístico.

Em resumo, a crítica kantiana se exerce na condição de uma propedêutica ao julgar os limites da razão pura. Entendida mais propriamente como crítica transcendental e não como uma doutrina, observa Kant, seu propósito é "fornecer a pedra de toque que decide sobre o valor ou desvalor de todos os conhecimentos a priori" (KANT, 1999, p. 65). De modo que, tal crítica, nas palavras de Kant, "é uma preparação para um órganon". Portanto, a crítica funciona na medida em que projeta o plano arquitetônico para a filosofia transcendental e revela que o cognoscível, "aquilo que posso saber", é o objeto empírico pensado $a$ priori em estruturas reflexivas do entendimento, este que, para Hegel, por sua vez, é uma razão finita e subjetiva. Cognoscíveis são, unicamente os fenômenos, que estão nos limites da experiência possível e que se distinguem da coisaem-si. Isso revela o pressuposto da radical separação entre sujeito e objeto, pois conhecer fenômenos, em Kant, é conhecer apenas por representação. Hegel censura, então, o 
subjetivismo kantiano, pois a possibilidade do conhecimento que, por sua vez, é meramente representativo, depende de uma razão estritamente subjetiva.

\section{A CRÍTICA IMANENTE HEGELIANA}

Exposto o criticismo kantiano em seu arcabouço arquitetônico para a filosofia transcendental, passaremos agora ao exame da crítica imanente em Hegel, a qual se desenvolve na experiência do saber como fenômeno.

Em seu Prefácio à Fenomenologia do Espírito, feita as ressalvas de que um prefácio não pode ser propriamente tomado como discurso filosófico, pois importa o percurso de exposição da verdade filosófica e não um certo esclarecimento preliminar do escopo de uma obra, Hegel explica a necessidade da Fenomenologia do Espírito como o necessário caminho de elevação do saber à Ciência. Para tanto, tal caminho se perfaz na medida em que o espírito individual percorre etapas de formação (Bildung) em direção ao Espírito Universal. Isso implica dizer que o caminho para a Ciência se faz assimilando conquistas culturais da história humana. A ideia de uma fenomenologia, do estudo dos atos da consciência no desenvolvimento do Espírito, se explica, portanto, por uma Razão que se desdobra em mundo (em um movimento de 
pôr a si mesma). A história da consciência pressupõe, destarte, o Espírito realizado:

A substância do indivíduo, o próprio espírito do mundo, teve a paciência de percorrer essas formas na longa extensão do tempo e de empreender o gigantesco trabalho da história mundial, plasmando nela, em cada forma, na medida de sua capacidade, a totalidade de seu conteúdo; e nem poderia o espírito do mundo com menor trabalho obter a consciência sobre si mesmo. É por isso que o indivíduo, pela natureza da Coisa, não pode apreender sua substância com menos esforço. Todavia, ao mesmo tempo em fadiga menor, porque a tarefa em si já está cumprida [...] (HEGEL, 2012, p. 42).

Sendo assim, a Fenomenologia é uma descrição "dos caminhos múltiplos e, contudo, ordenados, que a consciência segue quando tenta, dramaticamente, reconhecer-se como Espírito, isto é, quando aceita viver, como consciência, os momentos da sua constituição" (CHÂTELET, 1975, p. 72).

Temos, conforme Lima Vaz, dois fios condutores da Fenomenologia. O primeiro diz respeito às figuras que compõem a formação do sujeito para a ciência, "unindo dialeticamente as experiências da consciência que encontram expressões exemplares na história da cultura 
ocidental" (LIMA VAZ, 2012, p. 15). A Fenomenologia se desenvolveria, nesse sentido, não cronologicamente, mas de acordo com uma sucessão de paradigmas, ou seja, de acordo com a exposição de um conjunto de "fenômenos gerais da civilização", os quais aparecem, em sua forma abstrata, nas figuras da consciência individual (Cf. BORGES, 2009, p. 40). $\mathrm{O}$ segundo fio, por sua vez, une entre si os momentos da exposição das figuras; trata da necessidade interna da consciência de percorrer as etapas da experiência em direção ao Saber. O nexo do movimento é dialético. Isso posto, a Fenomenologia se configura, então, como um discurso sobre a busca da fundamentação filosófica a partir da rememoração de uma cultura racional cujo fim, do ponto de vista filosófico, é o Saber Absoluto:

Figuras e momentos tecem a trama desse original discurso hegeliano, que pode ser considerado a expressão da consciência histórica do filósofo Hegel no momento em que a busca de uma fundamentação absoluta para o discurso filosófico como autorreconhecimento da Razão instauradora de um mundo histórico - o mundo do Ocidente - pode ser empreendida não como a delimitação das condições abstratas de possibilidade, tal como tentara Kant, mas como a rememoração e recuperação de um caminho de cultura que desembocava nas terras do mundo pós-revolucionário, onde o sol do Saber 
absoluto - o imperativo teórico e prático de igualar o racional e o real - levantava-se implacável no horizonte (LIMA VAZ, 2012, p. 16).

O Saber absoluto, por seu turno, é a unidade final entre sujeito e mundo, "o pleno entendimento de que a substância tem de tornar sujeito" (TAYLOR, 2014, p. 242). A busca pela superação da ruptura entre sujeito e objeto atravessa o drama da consciência na sua tentativa de apreensão da realidade, de modo que seu caminho é marcado pelo desvio da cisão:

é necessário tomar o desvio que passa pela cisão, pelo "fazer a si mesmo outro". E, ao longo dessa via, sujeito e objeto surgem separados. Mas a separação, como não corresponde à verdade, traz consigo a inquietação da consciência, que não consegue nunca repousar dentro de si (HARTMANN, 1976, p. 381).

Ainda que seja objetivo do itinerário da consciência a superação entre sujeito e objeto isso não significa, no entanto, o pressuposto de uma radical separação entre esses dois momentos como se a consciência fosse uma estrutura $a$ priori ou transcendental. A consciência em Hegel apenas pode ser concebida como consciência de algo e, em seu sentido pleno, ela culmina na identidade entre sujeito e realidade. Não obstante, como tal identidade se efetiva por 
meio de um processo formativo, é preciso admitir que a consciência parte de uma forma fenomênica marcada pela oposição entre o momento do conceito e o momento do objeto.

Para Hegel só o Todo é a Verdade. E o todo nada mais é do que "a essência que atinge a completude por meio do seu desenvolvimento" (HEGEL, 1988, p. 17). Ora, isso implica que o Absoluto é sujeito ou devir-de-si-mesmo. Assim, conforme exposto acima, a expressão do Absoluto como Espírito compreende que a substância é essencialmente sujeito, sendo que o seu desenvolvimento é científico, pois sabe a si mesmo como sujeito. Diz Hegel: “o Espírito que se sabe assim desenvolvido como Espírito é a ciência" (HEGEL, 1988, p. 20). Isto é, o desenvolvimento do Espírito que sabe a si mesmo como sujeito é a ciência porque é a expressão efetiva da superação da cisão entre sujeito e objeto, a qual necessariamente é enfrentada pela consciência na sua formação para o universal em suas sucessivas tentativas de apreender a certeza do objeto (ou da realidade, que a princípio lhe aparece como exterior), significando o conhecimento da realidade como sujeito.

É assim que, na Introdução da Fenomenologia do Espírito, Hegel define como se põe o problema do conhecimento (Cf. HYPPOLITE, 2003, p. 20). À Fenomenologia compete, ademais, o conhecimento do Absoluto, no entanto, "no lugar de apresentar o saber do 
Absoluto em si e para si, Hegel considera o saber tal como este é na consciência; e é precisamente desse saber fenomênico, a criticar-se a si mesmo, que ele se eleva ao saber absoluto" (Cf. HYPPOLITE, 2003, p. 20). O saber fenomênico, ou o saber em devir, criticando a si mesmo, é a experiência da consciência, a crítica imanente.

$\mathrm{Na}$ Introdução da Fenomenologia, Hegel retoma a crítica sobre a concepção de um órganon filosófico que pretende "saber antes do saber". Para Hegel, nada mais é do que um contrassenso a ideia da experiência do conhecimento ser precedida pelo exame do próprio conhecer. Se a filosofia, para se certificar do seu domínio de conhecimento, precisa partir de um autoexame da consciência, esse autoexame apenas se justifica e se desenvolve a partir das formas fenomênicas da consciência, encontradas naturalmente no processo de conhecimento. Isso porque o autoexame na condição de uma crítica do conhecimento, não pode pressupor um sujeito cognoscente cuja autoconsciência já está dada e determina, aprioristicamente, o critério do conhecimento: isso significa abdicar da dúvida radical da qual parte toda crítica do conhecimento.

A representação do conhecimento como instrumento também é questionada pela crítica hegeliana. Representar o conhecimento como meio pode ser plausível a fim de acautelar-se diante de um possível erro, no entanto, "não se 
deve deixar de considerar igualmente por que não se deva cuidar de introduzir uma desconfiança nessa mesma desconfiança e recear que esse temor de errar já não seja o próprio erro" (HEGEL, 1988, p. 46). Essa cautela, para Hegel, pressupõe a separação entre o sujeito e o conhecimento e entre o conhecimento e o Absoluto. A concepção de conhecimento instrumental se limita, por conseguinte, a uma crítica estritamente epistemológica, de tal modo que se priva de conhecer objetos como "liberdade, espírito e Deus", os quais embora não pertençam à experiência sensível são, para Hegel, experimentados na consciência. No adendo do parágrafo $\$ 8$ da Enciclopédia, lêse:

É uma proposição antiga, que se costuma atribuir falsamente a Aristóteles, como se por ela devesse exprimir-se o ponto de vista de sua filosofia: "nihil est in intellectu quod non fuerit in sensu" - nada há no pensamento que antes não tenha estado no sentido, na experiência. Pode ser considerado apenas como mal-entendido que a filosofia especulativa não queira concordar com essa proposição. Mas inversamente ela também afirmará: "nihil est in sensu quod non fuerit in intellectu" - nesse sentido total geral de que o "nous", e em determinação mais profunda, o espírito, é a causa do mundo; e no sentido mais preciso de que um sentimento jurídico, 
ético-religioso é um sentimento e, portanto, uma experiência de tal conteúdo que tem sua raiz e sua sede só no pensamento (HEGEL, 1995, p. 48).

Hegel considera que compõem o conjunto de objetos da consciência as produções espirituais da humanidade, de modo que a Fenomenologia do Espírito se ocupará de experiências não apenas cognitivas, mas também estéticas, religiosas, sociais e morais, ao rememorar o trabalho do espírito no mundo. Ao acompanhar o saber em devir, a fenomenologia percorre a explicitação do espírito, tanto nos domínios teóricos, como nos domínios práticos.

É dessa maneira, submetida ao devir, que a experiência da consciência deve partir da consciência mais elementar empiricamente disponível. É a consciência natural que representará o primeiro estágio do exame. Essa primeira consciência se mostrará como um saber destituído de realidade, sendo este conhecimento fenomênico a sua verdade. Mas essa consciência simples deverá enfrentar o caminho da dúvida (ou do desespero) para a realização do conceito em superação à não-verdade do saber fenomênico. Observemos:

o ceticismo que se dirige a todo o âmbito da consciência como fenômeno torna o espírito apto para examinar o que é verdade, pois introduz o 
desespero com respeito às assim chamadas representações naturais, cogitações e opiniões que é indiferente denominar próprias ou estranhas e das quais a consciência que se move a realizar diretamente tal exame está ainda cheia e nas quais está embaraçada, sendo assim incapaz de levar efetivamente a cabo a tarefa que propõe (HEGEL, 1988, p. 49).

Sem abrir mão da radicalidade da dúvida e sem partir do pressuposto de uma razão pura, o exame do saber é possível a partir de uma crítica imanente às formas da consciência disponíveis e em devir. A explicitação da verdade só pode ser produto da análise que a consciência faz em si mesma desde o ponto de vista da não-verdade do saber como fenômeno, ou seja, desde o ponto de vista das diversas figuras assumidas pela consciência fenomênica. Assim, a dúvida radical proposta por Hegel, engendrará um autoexame que avaliará a apresentação de um saber fenomênico em sua não-verdade não como um "puro nada", como a expressão de um ceticismo vazio incapaz de produzir um novo saber, mas como "negação determinada", a saber, como explicitação de uma nova forma de consciência resultante da negação da sua forma anterior. Para Hegel, então, a experiência da consciência se efetua por si mesma ao percorrer a série total das figuras 
fenomenológicas: "a completude das formas da consciência não-real resultará por si mesma da necessidade e da concatenação do processo" (HEGEL, 1988, p. 49). Processo este cujo alvo é o estágio "onde o saber não tem mais necessidade de passar além de si mesmo, onde se encontra a si mesmo e onde o conceito corresponde ao objeto e o objeto ao conceito" (HEGEL, 1988, p. 49).

Hegel afirma, por conseguinte, que a consciência sofre. Sofre, em si mesma, "a violência que destrói toda satisfação limitada" (HEGEL, 1988, p. 50), pois a angústia diante da verdade a leva a tentar conservar a sua verdade unilateral que, inevitavelmente, perderá. Esse processo, de progressivo afastamento de uma consciência restrita, estabelece em si mesmo o critério a partir do qual se julga o saber fenomênico.

Para Hegel, a contradição vivida pela consciência entre a verdade que pretende afirmar e aquela que consequentemente deve aparecer, deve-se aos dois aspectos do saber como fenômeno. A consciência distingue algo de si mesma ao passo que se relaciona com esse algo - que é algo para a própria consciência. Temos o saber de alguma coisa como um aspecto e, como outro aspecto, a verdade desse saber que diz respeito ao que ele é em si. Ora, decorre que, o que é em si só pode ser para nós, pois alguma coisa é na medida em que é algo para a consciência, de modo que, 
perguntar pela verdade do saber é perguntar pela própria consciência. Diz Hegel:

Se denominarmos o saber conceito e denominarmos o existente ou o objeto a essência ou o verdadeiro, o exame há de consistir em ver se o conceito corresponde ao objeto. Mas, se denominarmos a essência ou o em-si do objeto conceito e, ao contrário, entendermos como objeto o conceito enquanto objeto, ou seja, tal como é para um outro, o exame consistirá então em ver se o objeto corresponde ao seu conceito. Vê-se perfeitamente que se trata de uma só e mesma coisa (HEGEL, 1988, p. 52).

Logo, na medida em que a consciência examina a correspondência do seu saber com o objeto, ela examina a si mesma, pois conceito e objeto estão nela mesma, assim, sendo ambos para a consciência, "ela mesma é a sua comparação" (HEGEL, 1988, p. 52). Por conseguinte, implica que, "se os dois momentos não se correspondem nessa comparação, tudo indica que a consciência deva mudar o seu saber a fim de torná-lo adequado ao objeto" (HEGEL, 1988, p. 52). Com efeito, mas mudar o saber significa mudar o objeto e, assim, a medida do saber precisa ser modificada para acompanhar o objeto no percurso do exame. Esse movimento que a consciência realiza em si mesma, a partir de seus dois momentos, trata-se de um 
movimento dialético que constitui o motor da própria crítica imanente. Hegel chama de experiência, pois, o movimento dialético descrito acima.

A crítica hegeliana é marcada, portanto, por um tipo de reflexão que, ao negar uma verdade primordial, admite que, para conhecer, é necessário já ter conhecido. E isso significa admitir o exame do conhecimento através das formas fenomênicas da consciência: o saber em devir. Nesse sentido, como afirma Habermas, o objetivo de Hegel é o conhecimento "que o criticismo afirma possuir sem qualquer mediação" (HABERMAS, 1987, p. 30). Ao criticar os pressupostos do conhecimento, Hegel desloca-o dos limites transcendentais ao passo que o retira do âmbito $a$ priori da possibilidade para o exame imanente fenomenológico.

Diferentemente ainda da crítica kantiana, cujo método epistemológico tem na ciência natural seu modelo, a crítica empreendida na Fenomenologia não pressupõe uma dada categoria de saber: ela deve avaliar o saber a partir do exame imanente à própria consciência que conhece, desde o ponto de vista das formas de consciência empiricamente disponíveis. Para Hegel, um saber se torna científico quando sua constituição é justificada pela sua autoexposição, ou seja, ser ciência requer um processo formativo de análise do saber também enquanto fenômeno. Visivelmente que, para tanto, Hegel concebe um arquétipo de consciência que, 
mesmo descentrada pelos momentos de contradição, é autorreferente. Por outro lado, expor que um saber só se afirma através do exame da manifestação de outros saberes, e isso por uma medida imanente, significa uma crítica que não lança mão de premissas dogmáticas, mas que, "dirige sua crítica de forma igualmente incondicional também contra si mesma, na medida em que não pode, simplesmente, pressupor seus parâmetros, com os quais fica em condições de examinar o processo cognitivo", diz Habermas (HABERMAS, 1987, p. 35-36).

Ao emergir da reflexão do devir histórico da consciência, a crítica em Hegel rompe, também, com a pressuposição da distinção entre razão teórica e razão prática. O sujeito cognoscente, no percurso da experiência, se manifestará igualmente como sujeito prático. A experiência do saber em devir é a reconstrução fenomenológica da constituição do espírito na história humana ao transitar, conforme Habermas, "pelo processo da socialização do indivíduo, pela história universal da espécie e pela história desta mesma espécie autorrefletindo-se nas formas do espírito absoluto, na religião, na arte e na ciência" (HABERMAS, 1987, p. 39). 


\section{CONSIDERAÇÕES FINAIS}

Observamos, então, que a noção de experiência em Hegel se constitui como uma crítica imanente, na medida em que é um exame realizado pela consciência nela mesma, desde suas formas fenomênicas ou desde o saber como fenômeno. Ao radicalizar a crítica do conhecimento sem pressupor uma saída primordial, a crítica em Hegel empreende uma autocrítica aos pressupostos da crítica transcendental kantiana. O sentido da crítica é, portanto, redefinido: a crítica imanente não pretende estabelecer condições apriorísticas do conhecimento e não se constitui como um órganon, mas se orienta para a produção de um conhecimento que é resultado de um percurso formativo que é, propriamente, a experiência da consciência.

\section{NOTAS}

1 Mestranda no Programa de Pós-Graduação em Filosofia da Universidade Federal da Bahia (PPGF-UFBA). E-mail: carlaoliveira.oliveira1@gmail.com.

2 O empreendimento da revolução copernicana na metafísica compreende perguntar sobre a possibilidade desta como ciência, ou 
seja, sobre a possibilidade de juízos sintéticos a priori na metafísica. A resposta implica em saber se a filosofia tem um objeto próprio de conhecimento, se diferenciando das ciências analíticas e empíricas. No entanto, não iremos explorar este ponto, fundamental, destacamos, da filosofia de Kant. Devido ao escopo deste artigo, nos limitaremos a tratar da sua epistemologia desenvolvida sobretudo na Analítica Transcendental, a qual fundamenta o conhecimento do tipo científico.

\section{REFERÊNCIAS BIBLIOGRÁFICAS}

BORGES, M. A atualidade de Hegel. Florianópolis: Ed. Da UFSC, 2009.

TAYLOR, C. Hegel. Trad. Nélio Schneider. São Paulo: Realizações Editora, 2014.

CHÂTELET, F. Hegel. Trad. Alda Porto. Rio de Janeiro: Jorge Zahar Editor, 1995.

HABERMAS, J. Conhecimento e Interesse. Trad. José N. Heck. Rio de Janeiro: Guanabara, 1987.

HARTMANN, N. A Filosofia do Idealismo Alemão. Trad. José Gonçalves Belo. Lisboa: Fundação Calouste Gulbenkian, 1976. 
HYPPOLITE, J. Gênese e estrutura da Fenomenologia do Espírito de Hegel. Trad. Sílvio Rosa. São Paulo: Discurso Editorial, 2003.

HEGEL, G. W. F. Enciclopédia das Ciências Filosóficas em Compêndio. Trad. Paulo Meneses. São Paulo: Loyola, 1995, p. 48 , v. I.

HEGEL. A Fenomenologia do Espírito. Trad. Henrique Cláudio de Lima Vaz e Antônio Pinto de Carvalho. São Paulo: Nova Cultural, 1988.

HÖFFE, O. Immanuel Kant. Trad. Christian Viktor Hamm e Valerio Rohden. São Paulo: Martins Fontes, 2005.

HOWARD, C. Dicionário Kant. Trad. Álvaro Cabral. Rio de Janeiro: Jorge Zahar Editor, 2000.

KANT, I. Crítica da Razão Pura. 5a Edição. Trad. Manuela Pinto e Alexandre Morujão. Lisboa: Fundação Calouste Gulbenkian, 2001.

KANT. Crítica da Razão Pura. Trad. Valerio Rohden e Udo Baldur Moosburger. São Paulo: Nova Cultural, 1999.

VAZ, Henrique C. de Lima. A significação da Fenomenologia do espírito [Apresentação]. In: HEGEL, G. W. F. Fenomenologia do Espírito. $7^{\text {a }}$ Edição. Trad. Paulo Meneses. Petrópolis: Editora Vozes, 2012. 